\title{
Improved persistence and adherence to diuretic fixed-dose combination therapy compared to diuretic monotherapy Bimal V Patel ${ }^{* \dagger 1}$, Rosemay A Remigio-Baker ${ }^{\dagger 1}$, Patrick Thiebaud ${ }^{\dagger 1}$, Ronald Preblick ${ }^{\dagger 2}$ and Craig Plauschinat ${ }^{\dagger 2}$
}

\begin{abstract}
Address: ${ }^{1}$ MedImpact Healthcare Systems, Inc., 10680 Treena Street, 5th Floor, San Diego, CA 92131, USA and ${ }^{2}$ Evidence Based Medicine, Novartis Pharmaceuticals Corporation, 59 Route 10, East Hanover, NJ 07936, USA

Email: Bimal V Patel* - bimal.patel@medimpact.com; Rosemay A Remigio-Baker - remigio_baker@hotmail.com;

Patrick Thiebaud - ptrck_thbd@yahoo.com; Ronald Preblick - ronald.preblick@bayer.com; Craig Plauschinat - craig.plauschinat@novartis.com

* Corresponding author †Equal contributors
\end{abstract}

Published: 6 November 2008

BMC Family Practice 2008, 9:61 doi:10.1186/147I-2296-9-61
Received: 8 February 2008

Accepted: 6 November 2008

This article is available from: http://www.biomedcentral.com/|47/-2296/9/6I

(C) 2008 Patel et al; licensee BioMed Central Ltd.

This is an Open Access article distributed under the terms of the Creative Commons Attribution License (http://creativecommons.org/licenses/by/2.0), which permits unrestricted use, distribution, and reproduction in any medium, provided the original work is properly cited.

\begin{abstract}
Background: Diuretics are recommended as initial treatment for hypertension. Several studies have suggested suboptimal persistence and adherence to thiazide diuretic monotherapy; this study compared patient persistence and adherence with hydrochlorothiazide (HCTZ) monotherapy to fixed-dose combinations containing HCTZ.

Methods: Patients with at least one prescription claim during $200 \mathrm{I}$ to 2003 for either HCTZ or one of the following fixed-dose combinations: angiotensin-receptor blockers/HCTZ (ARB/HCTZ), angiotensinconverting enzyme inhibitor/HCTZ (ACEl/HCTZ), or beta blockers/HCTZ (BB/HCTZ) were identified. Patients were required to be continuously benefit-eligible six months pre- and one year post-index date, and to have no prescription claims for any antihypertensive therapy six months prior to the index date. Patients were followed for one year to assess persistence, medication possession ratio (MPR), adherence (MPR $>80 \%$ ), and proportion of days covered (PDC) with initial antihypertensive therapy. Logistic regression was used to calculate adjusted odds ratios for persistence, adherence and PDC, adjusted for age, gender, business segment, RxRisk disease categories, average co-pay and concurrent cardiovascularrelated medication utilization.
\end{abstract}

Results: The study cohort consisted of 48,212 patients; $72.5 \%$ used HCTZ, I3.2\% ACEI/HCTZ, 9.3\% ARB/HCTZ, and $5.0 \%$ BB/HCTZ. Mean age was 53.7 years and $66.5 \%$ were female. A significantly lower proportion of patients using HCTZ (29.9\%) remained persistent with therapy at 12 months compared with ARB/HCTZ (52.6\%; OR = 0.37, Cl = 0.36, 0.38), ACEl/HCTZ (5I.4\%; OR =0.38, Cl = 0.37, 0.39), and BB/ HCTZ (5I.9\%; OR $=0.38,0.37,0.40)$. Similarly, PDC was lower for HCTZ patients $(32.5 \%)$ as compared to ARB/HCTZ (53.7\%; OR = 0.39, Cl = 0.37, 0.40), ACEl/HCTZ (50.9\%; OR = 0.42, Cl = 0.40, 0.43), and $\mathrm{BB} / \mathrm{HCTZ}(5 \mathrm{I} .3 \%$; OR $=0.44, \mathrm{Cl} 0.42,0.45)$. MPR was also significantly lower for HCTZ patients as compared to those using fixed-dose combination therapies.

Conclusion: Initiating HCTZ fixed-dose combination therapy with an ACEI, ARB, or BB was associated with greater persistence and adherence as compared to HCTZ monotherapy. Further research is needed to determine the relationship between improved persistence and adherence with blood pressure control. 


\section{Background}

Hypertension affects almost one in three American adults; age-adjusted prevalence in 2005 was estimated at 33.6\% $[1,2]$. Only $37 \%$ of patients with hypertension, and only slightly more than half (57\%) of those receiving antihypertensive treatment currently have their blood pressure (BP) controlled [1]. The Joint National Committee on Prevention, Detection, Evaluation, and Treatment of High Blood Pressure published its seventh report (JNC 7) in 2003 [3]. JNC 7 included the recommendation of thiazide diuretics, either alone or in combination with drugs from other classes, as initial therapy treatment of most patients with hypertension.

Patient persistence and adherence to prescribed antihypertensive therapy is a key component of hypertension management. Greater persistence with antihypertensive therapy has been associated with lower rates of long-term hypertension sequelae [4], as well lower health care resource use [5-8] and hospitalization rates [6]. In usualpractice settings, less than optimal persistence with antihypertensive monotherapy regimens has been well documented [9-13]. Several studies have indicated that initial monotherapy treatment with diuretics is associated with poorer patient persistence, compared to angiotensin-converting enzyme inhibitors (ACEI), angiotensin-receptor blockers (ARB), and beta blockers (BB). [9,11,13]. Tolerability and perceived side effects associated with antihypertensive medications may play an important role in patient motivation, and thus affect medication persistence [14]. Patients may complain of frequent urination upon initiation of diuretic therapy, and diuretics have been associated with side effects such as weakness, fatigue, palpitations, and electrolyte disturbances. Patients are often prescribed a lower dose of diuretic when used in combination therapy with an agent from another antihypertensive class, and combination low-dose therapy has been shown to increase BP-lowering efficacy and reduce adverse side effects associated with higher-dose monotherapy regimens [15]. Thus, the addition of a medication from another antihypertensive class to a diuretic may attenuate the side effects often seen with diuretics when used as monotherapy [15-17].

The purpose of this study was to compare patient persistence and adherence to hydrochlorothiazide (HCTZ) monotherapy versus fixed-dose combinations containing HCTZ and an ACEI, ARB, or BB in a natural (non-clinical trial) setting. This retrospective, longitudinal cohort study employed administrative pharmacy claims data to examine drug utilization in patients previously naïve to antihypertensive therapy who initiated therapy with HCTZ monotherapy, or fixed-dose ACEI/HCTZ, ARB/HCTZ, or BB/HCTZ.

\section{Methods}

This was a retrospective, population-based study which employed a pharmacy claims database from MedImpact, a large US pharmacy benefits manager (PBM) which administers prescription benefits for about 27 million persons across the US. Adult participants ( $\geq 18$ years) were eligible for study inclusion if they received $\geq 1$ prescription for HCTZ or fixed-dose combination ACEI/HCTZ, $\mathrm{ARB} / \mathrm{HCTZ}$, or $\mathrm{BB} / \mathrm{HCTZ}$ during the study identification period of January 1, 2001 through December 31, 2003. "Index drug" was defined as the first prescription therapy filled within the identification period, and the "index date" was defined as the date of the first index drug fill. Participants were required to be continuously benefit-eligible for at least 6 months preceding and 12 months subsequent to the index date. Patients were required to have no claims for any antihypertensive therapy during the 6 months prior to their index date.

Drug utilization was followed for 1 year subsequent to the index date, and analyses were performed relative to the specific index drug classes. Figure 1 includes definitions of utilization metrics, including persistence, medication possession ratio (MPR), adherence, proportion of days covered (PDC) and time to therapy discontinuation. For index drug classification purposes, patients who received prescription fills for antihypertensive medications in addition to the study index medication on their study index date were excluded.

RxRisk [18] methodology was used to identify the presence of other diseases. RxRisk identifies claims during the 6 months prior to the index date for medications used to treat specific conditions to identify co-morbidities (e.g. a pharmacy claim for an oral antidiabetic agent is used to identify the presence of diabetes). RxRisk disease categories were used (e.g. diabetes yes/no) to describe patient clinical characteristics, and for adjustment of statistical comparisons for the presence of co-morbid conditions.

To control for potential physician's treatment selection bias, a propensity score adjustment was performed. A multinomial regression model was constructed to estimate the probability of the observed treatment choice based on patient characteristics, including patient age, gender, RxRisk disease categories, and type of benefit coverage (i.e., Commercial, Medicaid, Medicare, and selfinsured). The inverse of this probability, or propensity score weight, was then used in study multivariable logistic and linear regressions. For MPR, multiple variable linear regression techniques were used in pairwise comparisons of means adjusted for independent variables, which included propensity weight, patient age, gender, RxRisk disease categories, type of benefit coverage, average copay, and concurrent cardiovascular-related medications 


\begin{tabular}{|l|l|}
\hline Days to Therapy & $\begin{array}{l}\text { The date of fill for the last prescription during the 12-month } \\
\text { study follow-up period prior to therapy discontinuation*, minus } \\
\text { the index fill date, plus the days' supply of the last fill date. For } \\
\text { patients who did not discontinue therapy with the index } \\
\text { medication class during the study period, this was measured as } \\
\text { the last prescription fill date plus days' supply of that } \\
\text { prescription fill, minus the index fill date. }\end{array}$ \\
\hline Persistence & $\begin{array}{l}\text { At monthly intervals post-index fill date (i.e. month 2, 3, 4...) } \\
\text { and for the 12-month study period overall, the percentage of } \\
\text { individuals remaining on therapy who did not discontinue* } \\
\text { therapy with the index class. }\end{array}$ \\
\hline \begin{tabular}{l} 
Medication \\
\hline Possession Ratio
\end{tabular} & $\begin{array}{l}\text { The sum of days' supply for all fills of the index hypertension } \\
\text { class during the follow-up period, divided by the duration of the } \\
\text { follow-up period (365 days), multiplied by 100 to express as a } \\
\text { percentage. }\end{array}$ \\
\hline Adherence & $\begin{array}{l}\text { The percentage of individuals having an MPR } \geq 80 \%, \text { and no } \\
\text { occurrence of discontinuation*, of the index class of } \\
\text { hypertension medication }\end{array}$ \\
\hline $\begin{array}{l}\text { Proportion of Days } \\
\text { Covered (PDC) at }\end{array}$ & $\begin{array}{l}\text { The percentage of patients who possess index class } \\
\text { medication on day 365 of follow up, considering the specific } \\
\text { time of each fill dates and corresponding days' supply. }\end{array}$ \\
\hline end of follow up & * Discontinuation is defined as ending therapy with the target medication class and not \\
receiving a fill for the target medication within 60 days after exhausting the days supply \\
from the prior prescription claim.
\end{tabular}

Figure I

Study utilization metrics and definitions.

utilized (i.e., other antihypertensive drugs not equal to the initial therapy subsequent to the index pharmacy claim date; and digitalis, nitrates, antiplatelet agents and antihyperlipidemics). Pairwise multiple logistic regression was used to calculate odds ratios to compare persistence, adherence, and proportion of days covered (PDC), adjusted for the same independent variables, using HCTZ monotherapy as the reference group. Although these statistical methods were used to control for important variables, crude statistics are included in the text and the tables for descriptive purposes, since statistical adjustment did not appreciably alter any values.

Persistence was evaluated using multivariable survival analysis techniques. Cox proportional hazards regression was employed to calculate hazard ratios (HR) to compare discontinuation for antihypertensive medications studied, adjusted for covariates. Discontinuation of therapy with the index medication was modeled using HCTZ as the referent. All analyses for this study were performed using SAS version 9.1.3 (SAS Institute, Inc, Cary, NC).

\section{Results}

The final study population was comprised of 48,212 patients newly initiated on antihypertensive therapy. Cohort descriptive characteristics are summarized in Table 1 . Overall, $67 \%$ were females and the mean age was 53.7 years. HCTZ users comprised $72.5 \%$ of the study cohort, while 13.2\% used ACEI/HCTZ, 9.3\% ARB/HCTZ, and $5.0 \% \mathrm{BB} / \mathrm{HCTZ}$. HCTZ and BB/HCTZ patients were generally younger than ACEI/HCTZ or ARB/HCTZ patients. Patients receiving HCTZ were more likely to be female than those utilizing fixed-dose combination therapy. The proportion of cohort patients with cardiovascular-related conditions or diabetes was higher for ACEI/ HCTZ and ARB/HCTZ than for HCTZ or BB/HCTZ.

Unadjusted results for antihypertensive medication utilization metrics are displayed in Table 2. Patients receiving HCTZ had the lowest persistence (29.9\%), compared to $52.6 \%$ for $\mathrm{ARB} / \mathrm{HCTZ}, 51.9 \%$ for $\mathrm{BB} / \mathrm{HCTZ}$, and $51.4 \%$ for ACEI/HCTZ. The MPR was highest for BB/HCTZ (62.1\%), followed by ARB/HCTZ (60.5\%), ACEI/HCTZ (58.3\%), and HCTZ (44.5\%). Adherence was lowest for HCTZ patients (24.2\%) and highest for BB/HCTZ $(43.9 \%)$. HCTZ patients had the lowest proportion of 
Table I: Study cohort descriptive characteristics $(N=48,2$ I2)

\begin{tabular}{|c|c|c|c|c|}
\hline \multirow[b]{2}{*}{ Characteristics } & \multicolumn{4}{|c|}{ Initial anti-hypertensive therapy } \\
\hline & HCTZ (N = 34,934, 72.5\%) & $\begin{array}{c}\text { ARB/HCTZ } \\
(N=4,469,9.3 \%)\end{array}$ & $\begin{array}{c}\text { ACEI/HCTZ } \\
(\mathrm{N}=6,388,13.2 \%)\end{array}$ & $\begin{array}{c}\mathrm{BB} / \mathrm{HCTZ} \\
(\mathrm{N}=2,421,5.0 \%)\end{array}$ \\
\hline Mean age in years $\pm S D$ & $53.6 \pm 15.3$ & $54.6 \pm 13.8$ & $54.3 \pm 13.9$ & $52.2 \pm 13.8$ \\
\hline \multicolumn{5}{|l|}{ Age in categories } \\
\hline $18-44(\%)$ & $10,296(29.5)$ & $1,006(22.5)$ & $\mathrm{I}, 486(23.3)$ & $712(29.4)$ \\
\hline $45-54(\%)$ & $9,769(28.0)$ & $\mathrm{I}, 457(32.6)$ & $2,021(31.6)$ & $780(32.2)$ \\
\hline $55-64(\%)$ & $6,423(18.4)$ & $1,006(22.5)$ & $\mathrm{I}, 469(23.0)$ & $505(20.9)$ \\
\hline $65-74(\%)$ & $4,500(12.9)$ & $570(12.8)$ & $824(12.9)$ & $256(10.6)$ \\
\hline $75-84(\%)$ & $2,925(8.4)$ & $327(7.3)$ & $443(6.9)$ & $115(4.8)$ \\
\hline 85 and above (\%) & $I, 021(2.9)$ & $103(2.3)$ & $145(2.3)$ & $53(2.2)$ \\
\hline Frequency female (\%) & $24,495(70.1)$ & $2,573(57.6)$ & $3,629(56.8)$ & $1,356(56.0)$ \\
\hline \multicolumn{5}{|l|}{ RxRisk ${ }^{a, b}$} \\
\hline Behavioral Health & $6,413(18.4)$ & $653(14.6)$ & $810(12.7)$ & $332(13.7)$ \\
\hline $\begin{array}{l}\text { Cardiovascular } \\
\text { Conditions }\end{array}$ & $2,012(5.8)$ & $435(9.7)$ & $874(13.7)$ & $128(5.3)$ \\
\hline $\begin{array}{l}\text { Gastric acid disorder, } \\
\text { IBS }\end{array}$ & $2,768(7.9)$ & $250(5.6)$ & $351(5.5)$ & $147(6.1)$ \\
\hline Asthma, Allergic Rhinitis & $2,590(7.4)$ & $196(4.4)$ & $301(4.7)$ & $79(3.3)$ \\
\hline Diabetes & $843(2.4)$ & 147 (3.3) & $281(4.4)$ & $23(1.0)$ \\
\hline Thyroid Disease & $2,193(6.3)$ & $230(5.1)$ & $321(5.0)$ & $108(4.5)$ \\
\hline $\begin{array}{l}\text { Rheumatoid Arthritis, } \\
\text { Gout }\end{array}$ & $1,273(3.6)$ & $120(2.7)$ & $171(2.7)$ & $50(2.1)$ \\
\hline \multicolumn{5}{|l|}{ Primary market segment } \\
\hline HMO & $24,562(70.3)$ & $2,644(59.2)$ & $4,656(72.9)$ & I,63I (67.4) \\
\hline Medicaid & 4,103 (II.8) & $125(2.8)$ & $300(4.7)$ & $112(4.6)$ \\
\hline Medicare & $2,285(6.5)$ & $227(5.1)$ & $355(5.6)$ & $122(5.0)$ \\
\hline Self-insured & 3,984 (II.4) & $1,473(33.0)$ & I,077 (16.9) & $556(23.0)$ \\
\hline Average copay $(\$)^{c}$ & $5.2 \pm 4.2$ & $22.8 \pm 19.0$ & $14.0 \pm 13.0$ & $9.2 \pm 8.7$ \\
\hline
\end{tabular}

a The 49 RxRisk categories were consolidated into 21 categories of which the top 7 most prevalent groups ( $3 \%$ threshold) are presented here. Behavioral health = anxiety and tension, bipolar, depression, psychotic illness, attention deficit disorder; Cardiovascular conditions: Cardiac disease, coronary \& peripheral vascular disease, heart disease, hypertension (does not include the target medications, digitalis, nitrates, anti-platelet agents or anti-hyperlipemic agents); Gastrointestinal (GI) disorders = Gastric acid disorder, irritable bowel syndrome

$\mathrm{b}$ Limited to antihypertensive medications of the same class as the index drug

days covered $(32.5 \%)$, and time to therapy discontinuation was longest for ARB/HCTZ patients $(240.1 \pm 140.3$ days).

Adjusted odds ratios for persistence, adherence, and days covered are found in Table 3. Compared to all fixed-dose combination therapy users, HCTZ patients were significantly ( $p<0.01$, all comparisons) less likely to be persistent, adherent, and to have medication "on hand" at the end of the study period. Patients receiving HCTZ were approximately $63 \%$ less likely to be persistent compared to ARB/HCTZ patients, $62 \%$ less likely to be persistent than ACEI/HCTZ patients, and 61\% less likely to be persistent than BB/HCTZ patients. Similarly, HCTZ patients were $60 \%, 54 \%$, and $50 \%$ less likely to be adherent as compared to BB/HCTZ, ARB/HCTZ, and ACEI/HCTZ patients, respectively. Odds ratios for days' covered indicated that HCTZ users were $61 \%, 59 \%$, and $56 \%$ less

Table 2: Unadjusted antihypertensive persistence and adherence

\begin{tabular}{|c|c|c|c|c|}
\hline Outcome measures & HCTZ & ARB/HCTZ & ACEI/HCTZ & $\mathrm{BB} / \mathrm{HCTZ}$ \\
\hline Persistence (\%) & 29.9 & 52.6 & 51.4 & 51.9 \\
\hline Adherence (\%) & 24.2 & 39.2 & 38.8 & 43.9 \\
\hline PDCa at end of follow-up (\%) & 32.5 & 53.7 & 50.9 & 51.3 \\
\hline$M P R^{b} \pm S D$ & $44.5 \pm 34.5$ & $60.5 \pm 32.7$ & $58.3 \pm 34.2$ & $62.1 \pm 34.1$ \\
\hline Days to therapy discontinuation $\pm S D$ & $164.5 \pm|4| .8$ & $240.1 \pm 140.3$ & $235.9 \pm 140.8$ & $238.2 \pm 140.9$ \\
\hline
\end{tabular}

aPDC denotes proportion of days covered at the end of the follow-up period. The percentage of patients who possess index class medication on day 365 of follow-up period.

bMPR denotes medication possession ratio. 
Table 3: Outcome measures - adjusted pairwise comparison of HCTZ monotherapy versus each fixed-dose combination therapy

\begin{tabular}{|c|c|c|c|}
\hline \multirow[b]{2}{*}{ Outcome measures } & \multicolumn{3}{|c|}{ HCTZ fixed-dose combination therapy } \\
\hline & ARB/HCTZ & ACEI/HCTZ & $\mathrm{BB} / \mathrm{HCTZ}$ \\
\hline Persistence (Odds Ratio, 95\% Cl) & $\begin{array}{c}0.369 a \\
(0.356,0.383)\end{array}$ & $\begin{array}{c}0.380^{a} \\
(0.368,0.393)\end{array}$ & $\begin{array}{c}0.382^{\mathrm{a}} \\
(0.370,0.395)\end{array}$ \\
\hline Adherence (Odds Ratio, 95\% Cl) & $\begin{array}{c}0.457^{\mathrm{a}} \\
(0.440,0.475)\end{array}$ & $\begin{array}{c}0.495^{\mathrm{a}} \\
(0.478,0.513)\end{array}$ & $\begin{array}{c}0.398^{a} \\
(0.385,0.412)\end{array}$ \\
\hline PDC at end of follow-up period (Odds Ratio, $95 \% \mathrm{Cl}$ ) & $\begin{array}{c}0.388^{a} \\
(0.374,0.403)\end{array}$ & $\begin{array}{c}0.415^{a} \\
(0.402,0.429)\end{array}$ & $\begin{array}{c}0.435^{\mathrm{a}} \\
(0.42 \mathrm{I}, 0.449)\end{array}$ \\
\hline MPR (HCTZ vs. fixed-dose) & $\begin{array}{c}44.4 \text { vs } 61.0 \\
\Delta=-16.6^{\mathrm{b}}\end{array}$ & $\begin{array}{c}44.6 \text { vs } 57.5 \\
\Delta=-12.9^{\mathrm{b}}\end{array}$ & $\begin{array}{c}44.5 \text { vs } 61.5 \\
\Delta=-17.0^{\mathrm{b}}\end{array}$ \\
\hline
\end{tabular}

a Significant difference in outcome measures between pairwise comparison with HCTZ users at $\mathrm{p}<0.05$.

${ }^{b} \mathrm{p}<0.0001$

likely to have medication on hand at the end of the study as compared to ARB/HCTZ, ACEI/HCTZ, and BB/HCTZ patients, respectively. Comparisons for MPR (Table 3) also revealed that HCTZ patients had lower adjusted mean MPR as compared to BB/HCTZ (difference $=-17.0$, $\mathrm{p}<0.0001)$, ARB $/$ HCTZ (difference $=-16.6, \mathrm{p}<0.0001$ ), and ACEI/HCTZ (difference $=-12.9, \mathrm{p}<0.0001$ ).
Cox proportional hazards model results are included in Table 4. Patients receiving HCTZ were more likely to discontinue the index medication class as compared to users of ACEI/HCTZ, ARB/HCTZ, and BB/HCTZ, adjusted for demographic and clinical covariates. Cardiovascularrelated conditions and patient copay were not significant predictors of therapy discontinuation in the proportional

Table 4: Results of Cox proportional hazards model for therapy discontinuation

\begin{tabular}{|c|c|c|}
\hline \multirow[b]{2}{*}{ Variable } & \multicolumn{2}{|c|}{ Study population $(\mathrm{N}=48,212)$} \\
\hline & Hazards ratio & P-value \\
\hline Age & 0.989 & $<.0001^{*}$ \\
\hline Female & 1.048 & $0.0002 *$ \\
\hline \multicolumn{3}{|l|}{ RxRisk categories ${ }^{\mathrm{a}}$} \\
\hline Anxiety and Tension, Bipolar Disorder, Depression, Psychotic Illness, ADD & 1.079 & $<.000 I^{*}$ \\
\hline Asthma, Allergic Rhinitis & 1.031 & 0.1891 \\
\hline Cardiac Disease, Coronary \& Peripheral Vascular Disease, Heart Disease, Hypertension ${ }^{b}$ & 0.973 & 0.2432 \\
\hline Gastric acid disorder, IBS & 1.004 & 0.8477 \\
\hline Rheumatoid Arthritis, Gout & 1.147 & $<.0001 *$ \\
\hline Thyroid Disease & 0.951 & $0.0426^{*}$ \\
\hline Diabetes & 1.158 & $<.000 I^{*}$ \\
\hline \multicolumn{3}{|l|}{ Business Type } \\
\hline HMO & $\mathrm{N} / \mathrm{A}$ & N/A \\
\hline Medicaid & 1.339 & $<.0001^{*}$ \\
\hline Medicare & 1.451 & $<.000 I^{*}$ \\
\hline Self & 1.056 & $0.0013^{*}$ \\
\hline \multicolumn{3}{|l|}{ Concomitant Other CVD-related Medications Used } \\
\hline Digitalis & 1.138 & $0.0086^{*}$ \\
\hline Nitrates & 1.224 & $<.000 I^{*}$ \\
\hline Antiplatelet Medications & 1.097 & 0.0502 \\
\hline Antihyperlipidemic Medications & 0.797 & $<.0001^{*}$ \\
\hline Average copayc & 1.001 & 0.3831 \\
\hline \multicolumn{3}{|l|}{ Target medication classes ${ }^{d}$} \\
\hline $\mathrm{ARB} / \mathrm{HCTZ}$ & 0.529 & $<.000 I^{*}$ \\
\hline ACEI/HCTZ & 0.536 & $<.000 I^{*}$ \\
\hline $\mathrm{BB} / \mathrm{HCTZ}$ & 0.532 & $<.0001 *$ \\
\hline
\end{tabular}

* Significant $\mathrm{p}$-value

a RxRisk categories shown in this table include the 7 most frequent disease states in the study cohort. All RxRisk disease categories were included in the model.

b This RxRisk category does not include the target medications, digitalis, nitrates, antiplatelet medications or antihyperlipidemics.

c Limited to HTN medications of the same class as the index drug.

d Reference Medication Class = HCTZ 
hazards model. An increased hazard of therapy discontinuation was observed for Medicaid and Medicare patients as compared to managed care patients, and for patients with diabetes.

\section{Discussion}

Our retrospective study found that the combination of another antihypertensive medication with HCTZ via fixed-dose combination therapy was associated with better patient persistence and adherence as compared to HCTZ monotherapy. HCTZ patients were 61-63\% less likely to be persistent, and 50-60\% less likely to be adherent, than patients who initiated antihypertensive therapy with fixed-dose ACEI/HCTZ, ARB/HCTZ, or BB/HCTZ therapy. Patients were more likely to stay on fixed-dose combinations longer than monotherapy, as mean time to therapy discontinuation was, on average, two and a half months longer for fixed-dose combinations than for monotherapy. To our knowledge, the current study is the first to compare persistence with HCTZ monotherapy to fixeddose HCTZ combination therapy in a "usual care" setting in the US.

A few other studies have used retrospective methods to evaluate combination therapy in "usual-care" settings outside of the US. Van Wijk et al, in a recent communitybased retrospective study using pharmacy dispensing records in the Netherlands, studied 2325 previously naïve patients who newly initiated antihypertensive therapy with a ACEI, BB, calcium channel blocker (CCB), or diuretic [19]. Only 39\% of patients used antihypertensive therapy consistently during 10 years of follow-up. More patients who initiated therapy with diuretics and BB discontinued compared to those who started with a CCB or ACEI. In this study, comparing patients who initiated with diuretics, those who started with fixed-dose combination therapy were $70 \%$ more likely to be persistent with therapy (OR 0.29; 95\% CI 0.14-0.54).

Another recent study comparing utilization for antihypertensive monotherapy versus fixed-dose combination therapy used a Canadian database, and found that during the first 6 months after treatment was initiated, persistence declined to 75\%; at the end of 3 years, only 55\% were persistent [20]. During the first year of follow-up, compared to diuretic monotherapy, patients prescribed other antihypertensive classes or fixed-dose combination therapy (HR $0.71 ; 95 \%$ CI 0.67 to 0.75 ) were found to have higher persistence [20]. Other studies comparing monotherapy regimens conducted in naturalistic settings have consistently found poorer compliance and/or persistence for diuretics as compared to other antihypertensive therapeutic classes [11-13,21,22]. Conlin and colleagues [9] followed patients from a large pharmacy benefits manager (PBM) and demonstrated that at 4 years post-therapy initiation, only $16 \%$ of diuretic patients were persistent, compared to $61 \%$ of ARB, $47 \%$ of ACEI, $41 \%$ of CCB, and $35 \%$ of BB patients.

Improving patient adherence and persistence with antihypertensive therapy may have a beneficial effect on blood pressure control. One recent retrospective study of 840 patients using antihypertensive monotherapy assessed the relationship between medication compliance and blood pressure control ( $<140 / 90 \mathrm{mmHg}$ or $<130 / 85 \mathrm{mmHg}$ for diabetic hypertensive patients) [23]. Patients received monotherapy with an ACEI $(27 \%)$, or CCB $(22 \%)$, BB $(20 \%)$, or diuretic $(11 \%)$ and were classified as having high $(80-100 \%)$, medium $(50-79 \%)$, or low $(<50 \%)$ medication compliance. High-compliance patients were $45 \%$ more likely to achieve blood pressure control than those with medium or low compliance after controlling for age, gender, and comorbidities.

Differences between antihypertensive drug regimens for patient medication adherence and persistence may have cost implications. Increased healthcare expenditures for nonadherent patients with hypertension in usual-care settings have been well documented [5-8]. In one study, Medicaid patients with an interruption of antihypertensive therapy consumed extra healthcare costs of $\$ 873 /$ patient during the first year [5]. Another study of both MCO and traditional fee-for-service patients from a large PBM found that better compliance with antihypertensive therapy was associated with a decreased risk of hospitalization and, thus, lower medical costs [6]. Addressing patient noncompliance with antihypertensive medication can thus play an important role in managing the costs of patient care for MCOs and other healthcare providers.

Retrospective analyses of administrative databases can provide information about patient behavior in a naturalistic setting that is difficult to assess in clinical trials, but it is important to note some study limitations. Since definitions of adherence and persistence may be expected to differ somewhat between studies, comparisons of medication utilization results across studies should be interpreted cautiously. As medical claims were unavailable to confirm hypertension diagnosis, some of the patients included may not have had a diagnosis of hypertension, and may have been prescribed a study medication for an unrelated diagnosis. This may have particularly influenced patient selection for BB/HCTZ users, as this combination has multiple indications and may be used more frequently in patients with stable angina or acute coronary syndromes. Drug utilization metrics were measured by prescription refill patterns and not actual drug taken by the patient; however, other studies have supported the evaluation of pharmacy claims data for such purposes $[24,25]$. Propensity score weighting was used in 
statistical analyses to control for selection bias, but it is possible that factors that were not available for analysis may have played a role in physician treatment selection. Since patient BP was not available for analysis, patients prescribed HCTZ in combination with a drug from another antihypertensive class may have had a higher baseline BP than those prescribed HCTZ alone; this information was unavailable for inclusion in the propensity score adjustment and may have influenced our study's results. It could be hypothesized that patients prescribed HCTZ alone may be "healthier" patients than those prescribed HCTZ in combination. While analysis of the prevalence of comorbid conditions between treatment groups suggests that this may be somewhat true for HCTZ monotherapy patients as compared to ARB/HCTZ and ACEI/ HCTZ patients, frequency of cardiovascular diagnoses and diabetes were similar for HCTZ and BB/HCTZ patients, yet persistence and adherence for $\mathrm{BB} / \mathrm{HCTZ}$ patients was much greater than for HCTZ patients. Statistical analyses were employed to control for such differences in patient co-morbidity and demographic characteristics, and significant differences in therapy discontinuation rates persisted. Since we identified patients using a 6-month prior eligibility criteria, it is possible that some patients may have discontinued previous AHY therapy prior to the 6 months or received another AHY therapy while a member of another health plan. It is possible that a patient who discontinued a study medication did so based on physician instructions, and this would have been incorrectly classified as non-persistence and may have influenced study results. Finally, our study included only fixed-dose combinations with HCTZ and excluded free combination regimens. Other studies have demonstrated improved persistence with fixed-dose antihypertensive combination regimens as compared to free combinations [26]; therefore, some of the persistence advantages found in our study of fixed-dose combinations may not be evident when using free combination regimens.

This study sought to evaluate patient utilization of HCTZ monotherapy as compared to HCTZ used in combination in patients new to antihypertensive therapy. Our findings are not meant to imply that all patients prescribed HCTZ as monotherapy are candidates for initial combination antihypertensive therapy; important prescriber and patient clinical factors play a role in the choice of initial antihypertensive therapy. However, our study provides additional information regarding the use of these regimens in a non-clinical trial setting, and when interpreted in the context of other literature suggesting poor patient adherence and persistence with HCTZ monotherapy versus monotherapy with other antihypertensive classes, provides important information to prescribers of antihypertensive medication.

\section{Conclusion}

In a naturalistic, non-clinical trial setting, our study suggested that patients who initiated new antihypertensive therapy with HCTZ in a fixed-dose combination with an ACEI, ARB, or BB may be more persistent than patients who initiated antihypertensive therapy with HCTZ alone. HCTZ patients were also less likely to be adherent as compared to fixed-dose combination patients, and to stay on therapy an average of 2.5 months less during the first year than patients using fixed-dose combinations. While additional research is needed to evaluate the impact of improved persistence and adherence with blood pressure control across practice settings, improving patient adherence and persistence with antihypertensive medication is an important approach to improving blood pressure control in the US.

\section{Competing interests}

Dr. Plauschinat is employed by Novartis Pharmaceuticals Corporation, the manufacturer of several medications indicated for the treatment of hypertension, and also owns stock in Novartis. At the time of the study, Dr. Preblick was employed by Novartis Pharmaceuticals Corp., and Dr. Preblick owns Novartis stock. Dr. Patel, Ms. Remigio-Baker, and Dr. Thiebaud have no competing interests to disclose.

\section{Authors' contributions}

$\mathrm{BP}$ and RP participated in conception and design of the study. BP, CP, RP, and RRB participated in writing and editing portions of the manuscript. RRB and PT participated in statistical analysis. All authors read and approved the final manuscript.

\section{Acknowledgements}

The authors would like to acknowledge Jenifer Wogen, MedMentis Consulting, LLC, for medical writing assistance in preparing this manuscript and R. Scott Leslie, Medlmpact, for his assistance with the data analysis and statistical support. Ms. Wogen received financial compensation from Novartis for her medical writing assistance. Mr. Leslie is an employee of Medlmpact.

This study was funded by Novartis Pharmaceuticals Corporation. Dr. Plauschinat is employed by Novartis Pharmaceuticals Corporation, the manufacturer of several medications indicated for the treatment of hypertension, and also owns stock in Novartis. Dr. Preblick is currently employed by Bayer Pharmaceuticals; at the time of the study, he was employed by Novartis Pharmaceuticals. Dr. Thiebaud and Ms. RemigioBaker were employees during the time of data analysis and manuscript preparation, but are no longer employed with Medlmpact. Ms. RemigioBaker is currently employed by University of California San Diego. Dr. Thiebaud is currently employed by Acumen, LLC.

Dr. Preblick and Dr. Plauschinat, as employees of the funding body, Novartis Pharmaceuticals Corporation, were involved in the aspects of the study listed above under 'Authors' contributions'. 
Portions of this study were presented as a poster at the American Society for Hypertension's $2{ }^{\text {st }}$ Annual Scientific Meeting and Exposition, New York, NY, May 2006.

\section{References}

I. Ong KL, Cheung BMY, Man YB, Lau CP, Lam KSL: Prevalence, awareness, treatment, and control of hypertension among United States adults 1999-2004. Hypertension 2007, 49:69-75.

2. Rosamond W, Flegal K, Friday G, Furie K, Go A, Greenlund K, Haase N, Ho M, Howard V, Kissela B, Kittner S, Lloyd-Jones D, McDermott M, Meigs J, Moy C, Nichol G, O'Donnell CJ, Roger V, Rumsfeld J, Sorlie P, Steinberger J, Thom T, Wasserthiel-Smoller S, Hong Y, American Heart Association Statistics Committee and Stroke Statistics Subcommittee: Heart Disease and Stroke Statistics 2008 Update. A Report From the American Heart Association Statistics Committee and Stroke Statistics Subcommittee. Circulation 2008, II7:e25-146.

3. Chobanian AV, Bakris GL, Black HR, Cushman WC, Green LA, Izzo JL Jr, Jones DW, Materson BJ, Oparil S, Wright JT Jr, Roccella EJ, National Heart, Lung, and Blood Institute Joint National Committee on Prevention, Detection, Evaluation, and Treatment of High Blood Pressure; National High Blood Pressure Education Program Coordinating Committee: The seventh report of the Joint National Committee on Prevention, Detection, Evaluation, and Treatment of High Blood Pressure: The JNC 7 report. JAMA 2003, 289:2560-2572.

4. Cramer JA: Consequences of intermittent treatment for hypertension: the case for medication compliance and persistence. Am J Managed Care 1998, 4: I563-1568.

5. McCombs JS, Nichol MB, Newman CM, Sclar DA: The costs of interrupting antihypertensive drug therapy in a Medicaid population. Med Care 1994, 32:214-226.

6. Sokol MC, McGuigan KA, Verbrugge RR, Epstein RS: Impact of medication adherence on hospitalization risk and healthcare cost. Med Care 2005, 43:52I-530.

7. Rizzo JA, Simons WR: Variations in compliance among hypertensive patients by drug class: implications for health care costs. Clin Ther 1997, 19:1446-1457.

8. Caro JJ, Speckman JL: Existing treatment strategies: does noncompliance make a difference? J Hypertens-Supplement 1998 1 2:533-537.

9. Conlin PR, Gerth WC, Fox J, Roehm JB, Boccuzzi SJ: Four-year persistence patterns among patients initiating therapy with the angiotensin II receptor antagonist losartan versus other antihypertensive drug classes. Clin Ther 200I, 23:1999-2010.

10. Wogen J, Kreilick CA, Livornese RC, Yokoyama K, Frech F: Patient adherence with amlodipine, lisinopril, or valsartan therapy in a usual-care setting. J Managed Care Pharm 2003, 9:424-429.

II. Marentette MA, Gerth WC, Billings DK, Zarnke KB: Antihypertensive persistence and drug class. Can J Cardiol 2002, 18:649-656.

12. Caro IJ, Speckman JL, Salas M, Raggio G, Jackson JD: Effect of initial drug choice on persistence with antihypertensive therapy: the importance of actual practice data. Can Med Assoc J 1999, 160:4I-46.

13. Elliott WJ, Plauschinat CA, Skrepnek GH, Gause D: Persistence, adherence, and risk of discontinuation associated with commonly prescribed antihypertensive drug monotherapies. J Am Board Fam Med 2007, 20:72-80.

14. Gregoire JP, Moisan J, Guibert R, Ciampi A, Milot A, Gaudet M, Côté I: Determinants of discontinuation of new courses of antihypertensive medications. J Clin Epidemiol 2002, 55:727-734.

15. Law MR, Wald NJ, Morris JK, Jordan RE: Value of low dose combination treatment with blood pressure lowering drugs: analysis of 354 randomised trials. BMJ 2003, 326:|427-34.

16. Nash DT: Rationale for combination therapy in hypertension management: focus on angiotensin receptor blockers and thiazide diuretics. South Med 2007, 100:386-392.

17. Neutel JM, Black HR, Weber MA: Combination therapy with diuretics: an evolution of understanding. Am J Med 1996, 101:6IS-70S.

18. Fishman PA, Goodman MJ, Hornbrook MC, Meenan RT, Bachman DJ, O-Keeffe Rosetti MC: Risk adjustment using automated ambulatory pharmacy data: the RxRisk model. Med Care 2003, 4I:84-99.
19. Van Wijk BL, Klungel OH, Heerdink ER, de Boer A: Rate and determinants of 10 -year persistence with antihypertensive drugs. J Hypertens 2005, 23:210I-7.

20. Perreault S, Lamarre D, Blais L, Dragomir A, Berbiche D, Lalonde L, Laurier C, St-Maurice F, Collin J: Persistence with treatment in newly treated middle-aged patients with essential hypertension. Ann Pharmacother 2005, 39: I 40I-8.

21. Thaker DJ, Frech F, Gause D, Zhang W: Patient adherence and persistence with antihypertensive agents: a comparison of agents in different therapeutic classes. Am J Hypertens 2005, 18:222A.

22. Patel BV, Remigio-Baker RA, Mehta D, Thiebaud P, Frech-Tamas $F$, Preblick R: Effects of initial antihypertensive drug class on patient persistence and compliance in a usual-care setting in the United States. I Clin Hypertens 2007, 9:692-700.

23. Bramley TJ, Gerbino PR, Nightengale BS, Frech-Tamas F: Relationship of blood pressure control to adherence with antihypertensive monotherapy in 13 managed care organizations. J Manag Care Pharm 2006, I 2:239-45.

24. Christensen DB, Williams B, Goldberg HI, Martin DP, Engelberg R, LoGerfo JP: Comparison of prescription and medical records in reflecting patient antihypertensive drug therapy. Ann Pharmacother 1994, 28:99-104.

25. Choo PW, Rand CS, Inui TS, Lee ML, Cain E, Cordeiro-Breault M, Canning C, Platt R: Validation of patient reports, automated pharmacy records, and pill counts with electronic monitoring of adherence to antihypertensive therapy. Med Care 1999, 37:846-857.

26. Dezii CM: A retrospective study of persistence with single-pill combination therapy vs. concurrent two-pill therapy in patients with hypertension. Manag Care 2000, 9(Suppl):2-6.

\section{Pre-publication history}

The pre-publication history for this paper can be accessed here:

http://www.biomedcentral.com/1471-2296/9/61/prepub

Publish with Bio Med Central and every scientist can read your work free of charge

"BioMed Central will be the most significant development for disseminating the results of biomedical research in our lifetime."

Sir Paul Nurse, Cancer Research UK

Your research papers will be:

- available free of charge to the entire biomedical community

- peer reviewed and published immediately upon acceptance

- cited in PubMed and archived on PubMed Central

- yours - you keep the copyright
BiolMedcentral 